\title{
Social cognitive perspective of gender disparities in undergraduate physics
}

\author{
Angela M. Kelly ${ }^{*}$ \\ Department of Physics and Astronomy and Institute for STEM Education, \\ Stony Brook University, 092 Life Sciences, Stony Brook, New York 11794-5233, USA
}

(Received 30 January 2015; published 1 August 2016)

\begin{abstract}
[This paper is part of the Focused Collection on Gender in Physics.] This article synthesizes sociopsychological theories and empirical research to establish a framework for exploring causal pathways and targeted interventions for the low representation of women in post-secondary physics. The rationale for this article is based upon disproportionate representation among undergraduate physics majors in the United States; women earned only $19.7 \%$ of physics undergraduate degrees in 2012 . This disparity has been attributed to a variety of factors, including unwelcoming classroom atmospheres, low confidence and self-efficacy, and few female role models in physics academic communities. Recent empirical studies have suggested gender disparities in physics and related STEM fields may be more amenable to social cognitive interventions than previously thought. Social psychologists have found that women improved physics self-concept when adopting a malleable view of intelligence, when they received support and encouragement from family and teachers, and when they experienced interactive learning techniques in communal environments. By exploring research-based evidence for strategies to support women in physics, precollege and university faculty and administrators may apply social cognitive constructs to improve the representation of women in the field.
\end{abstract}

DOI: 10.1103/PhysRevPhysEducRes.12.020116

\section{INTRODUCTION}

The proportion of women participating in physics majors in American universities has been chronically low. The American Physical Society reported in 2012 that women earned only $19.7 \%$ of physics undergraduate degrees and $36.4 \%$ of all undergraduate STEM degrees [1]. Their representation has also been low at the graduate level, earning $23 \%$ of Master's degrees in physics [2] and 18\% of doctorates [3], and in the transition to the physics workforce [4]. Recent reports have called upon academic institutions to formulate strategies for encouraging the participation of women in physics and other science, technology, engineering, mathematics (STEM) fields, since these students represent a vast talent resource that will contribute to economic innovation and global prosperity [5,6,7].

When exploring reasons for the low numbers of women in undergraduate physics, it is necessary to consider both precollege and university factors. Research has shown that $75 \%$ of female physics majors decided on their choice before or during high school, and $93 \%$ of women who have earned undergraduate physics degrees took physics in high school [8]. Girls' interest in physics tends to decline significantly during the high school years [9]. Though half of high school physics students are women $[3,8]$ and the

\footnotetext{
*angela.kelly@stonybrook.edu
}

Published by the American Physical Society under the terms of the Creative Commons Attribution 3.0 License. Further distribution of this work must maintain attribution to the author(s) and the published article's title, journal citation, and DOI. gap in international secondary physics performance has been declining [10], women have not remained in the pipeline to reach gender parity in postsecondary study.

Recent physics education research has explored social cognitive theories that may explain low rates of women's physics participation and how interventions have shown promise in mitigating the issue [11]. Social environments have significant effects on students' attitudes, motivations, values, and career choices. This article will build upon prior work by unifying several sociopsychological cognitive frameworks, aligning these frameworks with researchbased factors related to inequitable physics participation, and exploring empirical strategies for increasing physics persistence among women.

\section{SOCIOPSYCHOLOGICAL THEORIES RELATED TO PHYSICS PERSISTENCE}

The primary theoretical basis for this article is social cognitive career theory [12], rooted in Bandura's social cognitive theory [13,14], which suggested students' decision making about career paths has involved the interaction of self-efficacy, outcome expectations, and goal representations. Bandura's first work introducing social cognitive theory in 1986 is considered seminal in the field, generating over 50000 citations alone [14]. This theory established a model for human behavior, where individuals act to achieve a desired goal based on perceived outcomes within their sociocultural environments. His work proposed a triadic reciprocal view of causation, where the individual, her environment, and her behaviors are mutually reinforced constructs in contributing to personal goals. 
Social cognitive theory incorporates an agency perspective to human behavior, that is, individuals can intentionally produce desired outcomes through their own actions [15]. Students exercise agency as they make formative decisions about post-secondary study within the confines of their social contexts $[12,13,15]$. For example, Bandura claimed that women's career pursuits are sometimes limited by a sense of inefficacy in scientific disciplines that have been traditionally dominated by men, which may lead to alternative paths [16]. Exploring women's confidence, forethought, and choice of behaviors provides an insightful lens for understanding how their views of physics careers develop.

Social cognitive career theory, proposed by Lent, Brown, and Hackett [12], built upon Bandura's work by specifically applying it to both academic and career behavior. This theoretical framework encompasses the interrelated processes of choice, interest, self-regulated motivation, and performance. The theory is concerned with cognitive variables that link academic experiences and career-related choices [12]. These variables shed light on the development of a student's personal agency as she circumvents barriers in developing and pursuing academic and career goals. By emphasizing self-efficacy, outcome expectations, and goal representations, researchers have become aware of constraints that have potentially limited individual's career choices.

Social cognitive career theory has been cited as a valuable perspective for examining STEM-related academic choices, since there are several dynamic processes through which girls' experiences transform into career aspirations [17]. Women's participation in STEM is often linked to personal preferences and social pressures [18]. Consequently, the underlying interrelationships among individual, environmental, and behavioral variables will be examined to understand why women participate in physics at a disproportionately low rate.

To create a cohesive framework of social and cognitive considerations in evaluating women's participation in physics, several constructs will be explored and combined in a new thematic synthesis. These include (i) physics selfconcept and self-efficacy, (ii) expectancy value and the theory of planned behavior, and (iii) self-determination and motivation. Themes have been paired to combine cohesive constructs and streamline discussion of factors that may influence the underrepresentation of women in undergraduate physics. These subdimensions will provide the analytical organization for exploring causal pathways for gender disparities in physics, as well as research-based interventions. In doing so, this synthesis will provide a newly unified view of the application of social cognitive career theory to the choice of physics careers.

\section{A. Physics self-concept and self-efficacy}

Two important factors related to physics career choice are students' self-concept and self-efficacy. Self-concept is an individual's perception of her skills and capabilities in a specific academic domain, for example, whether the student views herself as a "physics person." It is more oriented towards past experiences since actions, consequences, and social interactions heavily influence selfperceptions [19]. Self-concept is formulated externally by comparing oneself to peers, and it is formulated internally by evaluating one's individual performance in physics as compared to other subjects [20]. Physics-related selfconcept has been shown to be one of the most significant predictors of physics achievement [21] and career aspirations [22]. Traditionally, women have possessed a lower self-concept in the physical sciences even after controlling for achievement [23].

Bandura defined self-efficacy as "people's judgments of their capabilities to organize and execute courses of action required to attain designated types of performances" [14] (p. 391). It is more future oriented than self-concept since it is focused on one's conviction that a specific target can be achieved [19], for example, achieving a high grade in a physics course. Physics self-efficacy is developed by several sources, including mastery experiences, observing role models, social persuasion, and emotional states such as anxiety and stress [24]. Similar to self-concept, selfefficacy has also been a significant predictor of physics understanding, course achievement, and persistence in major $[25,26,27]$. Task self-efficacy is typically dependent upon a related self-concept within the academic domain [28], suggesting that these factors are mutually reinforced.

\section{B. Expectancy-value model and theory of planned behavior}

Social cognitive career theory also relates career choice to outcome expectations, or the anticipation of probable results from chosen actions. These achievement-related choices are known as goal representations [12]. This construct is further explained by the expectancy-value model, which suggests that these behaviors are based upon two considerations: the expectancy of actual outcomes, and the importance or value attached to that choice [29]. Research has shown that expectancies of successful performance in physics have largely predicted persistence in the field [30]. Students generally do not choose career paths in which they do not anticipate doing well. Unfortunately, women have often underestimated their likely performance in physics more so than men, even when no differences were evident in physics achievement and ability [31-33]. For example, Haussler and Hoffman employed regression analysis with data collected from 73 secondary students and determined that students' interest in physics was most related to self-perceived competence in the subject, which was lower for women than men [32]. Also, women's preferences were an important explanatory factor in STEM persistence. Ceci et al. argued that women's interests best explained career choice in math-intensive 
science fields, as opposed to latent discriminatory practices, although these choices could be better informed through additional education about careers in the physical sciences [34]. Women may not choose physics if they do not recognize its relevance and social value early in their academic experiences [18].

The theory of planned behavior [35], formulated by social psychologist Ajzen, builds upon the expectancyvalue model by suggesting that one's controllability of a predicted behavior must be predicated upon self-efficacy. This theory states that human behavior is guided by likely consequences, the normative expectations of others, and beliefs about inhibiting factors. Physics may be viewed as an achievable career choice but students must also have confidence they can overcome potential obstacles along the way. Resilience and social support have been critical for some women planning careers in male-dominated fields such as physics [36].

\section{Motivation and self-determination}

The final piece of social cognitive career theory within this sociopsychological framework is motivation, defined with respect to science learning as "an internal state that arouses, directs, and sustains science-learning behavior" [37] (p. 3). Related variables include persistence, direction, and school achievement [38,39]. Motivation is critical to continue along a career path in physics. This motivation can be intrinsic, where students make the choice because physics is personally enjoyable and desirable, or extrinsic, with external factors driving the decision. Intrinsic motivation is not tied to a separate consequence, whereas extrinsic motivation is associated with a distinct outcome [40]. Gender differences have been observed in motivational factors, with women placing more value on intrinsic interest [41,42]. This intrinsic motivation can also be based upon feelings of satisfaction that may arise from experiencing mastery (resulting in a stronger self-concept), since there is a basic psychological need to feel competent [39].

Self-determination is inherently related to motivation, controllability, competence, and self-efficacy. Selfdetermination theory, proposed by psychologists Deci and Ryan, is defined as an approach to understanding motivation, whereby empirical methods are employed to study an individual's psychological resources for selfregulating behavior [40]. According to self-determination theory, intrinsic motivation and autonomy are a powerful combination in influencing career choice. Students who are capable of self-regulating behaviors that lead to a desired career path are more likely to sustain personal commitment and persistence [39]. Research has shown that women often act upon positive self-perceptions and the ability to control their own destiny in choosing STEM careers [28].

Figure 1 summarizes the proposed theoretical framework guiding this analysis. In the context of this review, social cognitive career theory provides the basis for explaining

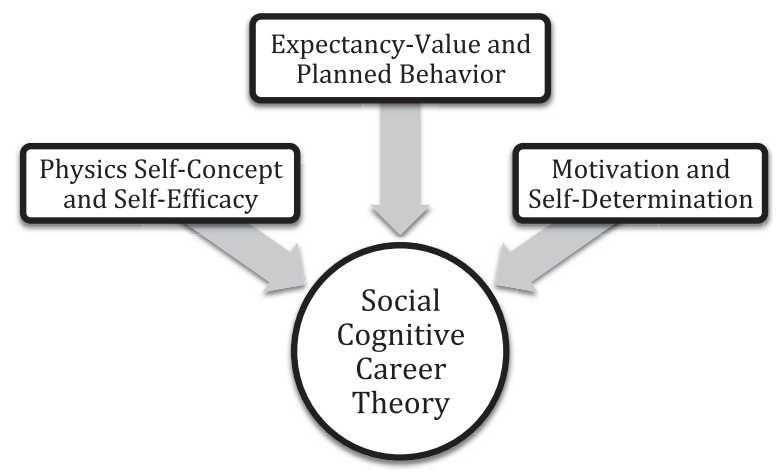

FIG. 1. Proposed new framework of sociopsychological theories related to women's physics persistence.

women's choices about physics-related career paths. This process involves one's evaluation of her own self-efficacy and self-concept, that is, whether she views herself as a competent physics achiever and whether she believes she can succeed in tasks leading to a physics career. The decision-making process also involves choosing behaviors that will lead to a desirable career outcome, in this case, evaluating whether a physics career is attainable and subsequently pursuing the targets necessary to reach the goal. Finally, women must be intrinsically motivated and self-directed to continue on the physics career path. These sociopsychological components of the decision-making process will shed light upon strategies for making physics a more attractive choice for women in post-secondary study and careers.

\section{Limitations of social cognitive career theory as an explanatory framework}

Although Bandura asserted that social cognitive theory is operationally generalizable in terms of both personal and collective agency [16], the theory does not necessarily challenge institutional constraints such as the established physics culture. The social cognitive career theory of Lent $e t$ al. proposed that gender and ethnicity are socially constructed, and differential learning opportunities for underrepresented groups may impede self-efficacy development and career-related skill acquisition [12]. Although Lent's work alludes to the phenomenological role of the individual in interpreting supports and barriers to career choices, it may not explain more nuanced identity-related constructs related to physics accessibility for women.

Other researchers have explored sociocultural theories as an explanatory lens for women's underrepresentation in physics and STEM in general. Such studies, in the tradition of critical theory, have challenged power structures and the reproduction of inequitable classroom practices. For example, Carlone challenged the sociohistorical legacy of "prototypical science education" by encouraging the adoption of physics curricula that allow students to develop identities as practitioners of science [43]. Calabrese Barton 
has explored the transformation and empowerment of girls in science by leveraging their particular experiences and knowledge; much of her work employed critical ethnography to highlight the values and practices of these students in urban communities [44-46]. These researchers and others [47-49] have incorporated the concept of identity in the face of institutional and environmental power differentials, along with support for specific interventions. The identity perspective is beyond the scope of this review but it provides both complementary and alternative frameworks for analysis of the underrepresentation of women in STEM disciplines.

The following section will explore factors related to gender disparities that fall within the sociocognitive framework of analysis.

\section{CONTRIBUTING FACTORS TO GENDER DISPARITIES IN PHYSICS EDUCATION}

A considerable body of research has explored possible influences on the gender gap in undergraduate physics participation. Such factors have included personal assessment of physics ability, career preferences, and external factors such as familial and school-based support. The following sections will describe empirical explanations for the disparity within the framework of sociopsychological influences.

\section{A. Self-assessment}

Career choice is largely dependent upon one's selfassessment of her capability for success within the domain. Overall physics self-concept is a reflection of one's ability, while physics self-efficacy is a personal assessment of the potential for success in future physics study. Interest in physics has been correlated to students' perceptions of being good achievers [41]. Consequently, a woman's view of her own capacity for achievement may be paramount in whether she chooses physics as a career path.

A pervasive theme in prior research relates to women's feelings of inadequacy in physics classrooms and departments. Many studies have reported the tendency of women to underrate their physics ability while men do not, despite similar measured proficiencies [28,42,50-53]. Girls in secondary school have been less likely to choose physics as an elective because many often doubted their ability to succeed [52]. Angell et al. conducted a mixed methods study with over 4000 secondary students and found that girls were more hesitant in choosing physics and questioned their ability to succeed in the course [53]. This hesitancy may be evident in research analyzing science classroom behaviors. For example, Guzzetti and Williams qualitatively studied discussion and behavior patterns in two high school physics classrooms, and found that girls were often fearful of being wrong or refuted in class discussions [54]. Girls were less likely to challenge others and posed such refutations as questions. In addition, Guzzetti's results were consistent with Tobin's findings [55] that girls were less likely to actually operate laboratory equipment. These researchers claimed that socially learned gender norms should be challenged by both students and teachers to promote intellectual safety in the classroom. Women in physics and engineering careers have proven to be successful in navigating the social identity threats that potentially impede self-confidence $[36,56]$.

\section{Negative stereotypes}

Subtle social suggestions and nonconscious biases have often reinforced the notion that physics is more suitable for men than women $[6,56,57]$. These stereotypes have been persistent and even evident before high school. Farenga and Joyce's study of 427 9-13 year olds revealed that both sexes perceived science and technology as more appropriate careers for boys ( $p<0.001$, effect size with Cohen's $d=0.70$ ); the effect size was even larger when students were asked specifically about the physical sciences ( $p<0.001$, Cohen's $d=1.25$ ) [58]. Mujtaba and Reiss, in a study of over 5000 students, found these stereotypes became more entrenched in later years, when girls have been less likely to receive encouragement to continue in physics from their secondary teachers $(p<0.001$, Cohen's $d=0.337$ ) [52].

Researchers have suggested such encouragement may be rooted in the physical stereotypes of how physicists are supposed to appear. Scientific competence has often been judged by how one presents herself, with some women in qualitative studies reporting that expressions of femininity have resulted in their own self-exclusion from the physics culture [48,57]. Ong reported that perceived scientific competence for women in physics has often been based upon physical characteristics such as content of speech, style of clothing and hair, and air of confidence [48]. Stereotypes have contributed to the imbalanced gender composition of the field, which has made physics an undesirable choice for some women [59].

The interaction of social and environmental influences has often resulted in women's awareness of negative stereotypes regarding their potential for physics performance and participation. This awareness, known as stereotype threat, has often resulted in the underperformance of women in academic fields in which they have been traditionally underrepresented [60]. Well-known social psychologists such as Aronson, Steele, Good, and Spencer have explored this construct in numerous studies of STEM disciplines $[61,62,63,64]$, and Marchand and Taasoobshirazi performed one of the only studies of stereotype threat in the context of women's performance in physics [65]. In their study, 312 high school students were asked to complete mechanics problems and identify their gender, grade, age, and ethnicity. Girls performed significantly lower in situations where stigma consciousness was activated, with ANCOVA results 
showing a statistically significant difference between boys' scores in the stereotype threat condition $(M=1.33$, $\mathrm{SD}=1.02)$ and girls' scores $(M=0.78, \quad \mathrm{SD}=0.75)$. This difference was not significant without the stereotype threat condition present, in this case, including a statement in the assessment that boys tend to perform better than girls in physics. This study revealed the added pressure from selffulfilling a pervasive stereotype interfered with performance in physics. This and other studies have shown some women may have dropped domain identification with STEM to avoid evaluative threat [61,64], though more research is needed in physics education specifically. The social pressure of domain identification has been mediated with greater domain self-efficacy and an accepting academic environment [62].

\section{Social atmosphere in physics learning environments}

Negative self-perceptions have often been correlated to the social atmosphere in physics academic environments. Social negotiation is essential in constructing science knowledge, and this requires a supportive classroom culture. Research by Zohar and others has shown women are more likely to use communal verbal strategies in physics classroom talk, taking turns and seeking consensus. These mixed methods studies suggested women sometimes avoid argumentation and retreat into silence when faced with competitive verbal interactions and aggressive argumentation [66,67]. In another exploratory study, women were more likely than men to experience communication anxiety in the physics classroom, evidenced by high scores on the Personal Report of Communication Apprehension instrument. This apprehension level was negatively correlated to mastery of conceptual physics concepts [68]. Other mixed methods research by Zohar has shown women to prefer small group discussions in the search for physics meaning, the avoidance of disputes, and non-authoritarian teaching styles [69]. At the collegiate level, many women tend to value a welcoming and supportive environment with open communication between faculty and students in physics departments [70,71].

Negative social atmospheres in science classrooms have lead to science anxiety - the feeling of tension or stress that interferes with learning science [24]. Koul et al. employed factor analysis and ANOVA in data collected from 1438 students to determine that women had higher levels of anxiety about failing physics than men $(F=78.96$, $p<0.01$ ), though their anxiety lessened when actually participating in a physics course [42]. Udo et al. administered the Science Anxiety Questionnaire [72] to 273 physics undergraduates and reported through multiple regression analysis that physics anxiety was particularly lessened for women taking an interactive course with a female instructor [73]. However, they noted that physics anxiety for both men and women takes root well before college physics and should be mediated in precollege educational settings.

\section{B. Preferences}

Motivation, a key component of physics career choice, is dependent upon the intrinsic appeal of the academic domain. Women will be more likely to choose physics if they find the subject interesting and relevant to their lives. Research has shown that women often feel disconnected to physics for a variety of reasons.

Students' career intentions in STEM have been significantly influenced by personal interests [74]. However, women and men have expressed varying levels of interest in physics topics. Many studies have emphasized the need for women to see the authenticity, or situated meaning, of physics concepts; otherwise their interest tends to diminish [41,75-77]. Girls have shown greater interest in physics topics that have social relevance $[9,41,78]$. For example, one study reported that girls most valued learning about radiation and health in a pilot physics curriculum, since it gave social purpose and relevance to their learning; their statistical gains in knowledge in this topic $(p<0.001)$ were greater than any other [77]. The perceived intrinsic value of physics lessons has been correlated to physics performance and persistence [52].

The presence of role models has also contributed to the career preferences of women. Studies have highlighted the value of both male and female physics faculty serving as role models and advisors, especially when their enjoyment of life outside of work is apparent [56]. However, the lack of women in the ranks of physics teachers and professors reinforces the stereotype that physics is a male domain. Women constituted $9.1 \%$ of physics faculty in the top 40 research universities in the U.S. in 2007 [79]. This is problematic considering the significant impact that female departmental faculty have had on the choice of major for college women [80]. The proportion of women has been increasing for high school physics teachers in the U.S., $37 \%$ of whom were women in 2013 [81]. Students who have chosen physics majors have been more likely to relate to their secondary physics teacher [82], so it is encouraging that the proportion of female high school physics teachers is on the rise.

\section{External influences}

Social influences are particularly important for women who choose to study physics. Research has shown that career decision making is often dependent upon the encouragement (or discouragement) of family, peers, and teachers. These influences are critical factors in the development of physics self-concept. Women have been more likely to rely upon support from social networks and some studies have shown they are more sensitive to the perceptions of others [50]. 
Elective enrollment in physics has been associated with the cultural and social capital of women's families [51]. Parental support has been cited as a critical factor for women choosing to pursue physics $[36,70,83,84]$. Hazari, Sadler, and Tai found significant mean differences between female and male university physics students $(N=2,755)$ regarding affective variables such as supportive home environment $(p<0.001$, effect size $=0.21)$, encouraging parents $(p<0.001$ for mother and $p<0.01$ for father), and an encouraging science teacher $(p<0.001)$ [83]. Family role models have been an important source of self-efficacy for women in STEM fields, since qualitative research has demonstrated the proximal presence of a successful scientist can increase one's perceived likelihood of success and satisfaction in the field $[42,85]$. Similarly, highly educated parents and high socioeconomic status have been associated with physical science persistence; family-oriented goals have also been a major consideration in decision making [28]. Research has shown that familial influence on women's STEM course choices is significant while is it not so for men [86]. Leslie, McClure, and Oaxaca reported that women experience "other directedness" (what others think of them) more so than men, suggesting that trusted networks of family and peers provided frequent guidance for their career choices [28].

Physics teachers have been enormously influential in women's decisions to study physics, though sometimes teaching styles and classroom atmospheres have had a negative effect. Schuck and Fish found that physics courses and how they are taught had the largest negative impact on women's perceptions of physics [87]. Criticisms of STEM faculty pedagogy have contributed significantly to choice of major; such criticisms included harsh, competitive grading systems, densely packed curricula, and a lack of teaching for conceptual understanding $[67,88]$. Women have often been intimidated in physics classrooms, participating to a lesser degree in hands-on laboratory tasks and class discussions [54,55]. Jansen et al. reported data analyzed through a latent regression model $(N=4,891)$, whereby interactive learning and hands-on tasks had a positive impact on physics self-efficacy [89]. Some women have also viewed many physics teachers as authoritarian, undemocratic, and inflexible [75,82,90]; autonomy is necessary for self-directed learning and the growth of intrinsic motivation.

Figure 2 illustrates the previously described factors that have contributed to gender disparities in physics. Pervasive themes related to sociocognitive variables are highlighted as they relate to the three main facets of the framework. The most commonly cited reason impacting women's physics self-efficacy and self-concept is their tendency to underestimate their ability in the domain. The physics performance self-perceptions of women were reported to be consistently lower than those of men, despite similarities in measured achievement. This sense of inadequacy may be

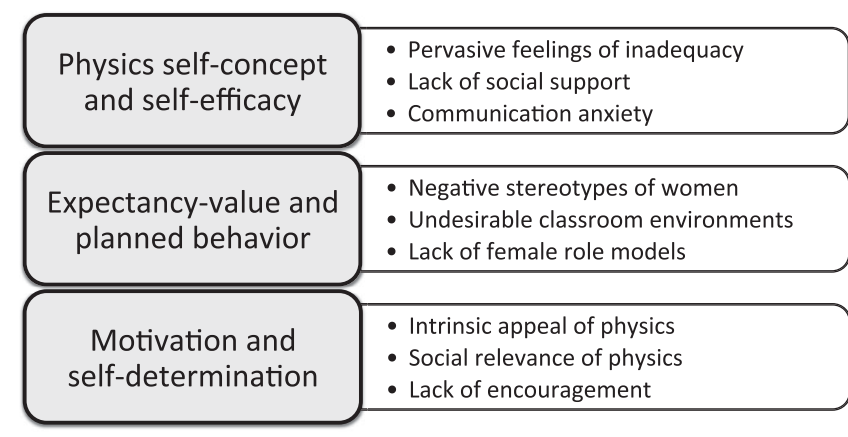

FIG. 2. Sociopsychological theories related to factors contributing to gender disparities in physics.

related to lack of encouragement from family and faculty, cold and competitive classroom environments, socially ingrained stereotypes of physicists, and the need to understand the social relevance of physics in their everyday worlds. These variables fit within the sociocognitive framework, suggesting the reciprocal interactions among personal and environmental factors influence women's intentions to pursue physics-related career paths. However, there is a broad research base that has explored ways to improve women's participation in post-secondary physics.

\section{STRATEGIES FOR INCREASING WOMEN'S PARTICIPATION IN PHYSICS}

Empirical studies have suggested gender disparities in physics and related STEM fields may be more amenable to social cognitive interventions than previously thought [11]. Most successful interventions involved teacher-initiated reforms rooted in reformed pedagogical practice and improved classroom climate. Other treatments addressed curricular structure and mechanisms for institutional support. These strategies are related to sociocognitive considerations for women evaluating career choices.

\section{A. Pedagogical and classroom-based strategies 1. Theories of intelligence}

Women have often underestimated their physics abilities, and their self-confidence has diminished with higher levels of physics education [32]. While their physics participation has reached parity in high school physics courses, there is a precipitous decline in physics participation in college and beyond. The leaky pipeline potentially contributes to social views of who can succeed in physics [91]. Women's awareness of negative stereotypes has been shown to trigger impaired academic performance $[60,61,65,92]$.

To counter stereotype threat and low physics selfconcept and self-efficacy, researchers have proposed shaping theories of intelligence, particularly among women and underrepresented students. That is, they have communicated to students that intelligence is malleable rather than 
fixed, making them less susceptible to stereotype threat. This theory was first proposed by Dweck [93] and has been applied as a mediating strategy for STEM underrepresentation of women [92,94]. A malleable (or incremental) theory of intelligence counters the notion that ability is inadequate and determines all outcomes. Students who have embraced the malleable view believe that hard work and perseverance are necessary to master challenging concepts [95]. This contradicts the fixed view of intelligence, a helpless mindset where students believe that their own ability is inadequate and underestimate their power to improve with effort and persistence. Students who have been trained in the incremental view that intelligence is expandable have increased their achievement and reported they enjoyed their academic work more [64,92]. Physics teachers can implement this strategy by emphasizing the value of effort in combating learned helplessness [33]. Students can be instructed about alternative problem solving methods, encouraged to form study groups, and personally approached about ways to persist and improve. If students believe they can control academic outcomes, and view difficulties as opportunities for learning, they will be more likely to develop a stronger self-concept and goal orientation [95]. However, more research is needed in subjects such as physics to explore domain-specific strategies.

\section{Positive learning atmospheres}

Physics teachers are instrumental in creating welcoming and engaging classroom environments. Women have been more responsive to socially competent physics teachers who are knowledgeable about conceptual challenges in physics understanding, and are willing to empower students by employing active learning techniques. For example, Labudde and Herzog performed a mixed methods study and found that achievement can be increased by the integration of student misconceptions, student-centered instruction, and more in-class discussion about physics. These strategies improved performance for both men and women, suggesting that acknowledging alternative ways of knowing can reach across gender lines to engage a larger pool of potential physicists [75]. Physics education research has explored many pedagogical and classroombased factors that have contributed to improving both women's and men's engagement with physics.

Much research has shown the value of communal, collaborative learning environments for women. These spaces are characterized by frequent discussion, small group interaction, and hands-on activities. Social negotiation has been found to be critical in learning physics, and women have often expressed their preference for more opportunities to express themselves and establish consensus $[66,75,94]$. However, women have been found to be intimidated by competitive argumentation with men [66,69]. Physics teachers need to encourage and monitor verbal interactions to avoid these feelings of overpowerment. Potential strategies include involving students in actively shifting classroom dynamics, perhaps by having them record the types and frequencies of social interactions. They may be empowered by suggesting ways to address observed inequities [54,55]. In physics classroom discussions, women were reportedly more likely to use consensus-driven verbal strategies, seek affirmation, and raise objections indirectly through questions [66]. Physics teachers may guide discussions carefully to foster a supportive classroom atmosphere where distinct viewpoints and communication styles are valued [96]. For example, Stadler et al. proposed that group discussions should openly support the participation of men and women, the use of analogies and anthropomorphisms, and the expression of ideas through writing [97]. These strategies acknowledge alternative ways of knowing physics and will create more welcoming physics classroom atmospheres for all.

There are other aspects of group discussion and interactive learning that have been shown to foster the engagement of women. In terms of questioning, physics teachers should ask for exploratory responses equally from men and women, and should use the same name conventions for both [56]. Physics teachers should elicit prior knowledge when introducing topics - this communicates that all students' experiences and ideas are valued $[25,75]$. Students should be allowed to selfselect cooperative groups, both to foster autonomy and to avoid the perception that groups were determined with a fixed-ability mindset $[66,68,87,96]$. These strategies were found to have contributed to the overall sense of a nonauthoritarian physics learning environment. Women have demonstrated their desire for democratic classrooms in establishing their self-concept, self-efficacy, and selfdetermination $[28,69,96]$.

Certain pedagogical choices have been conducive to improving women's attitudes and performance in physics. For example, Mazur's work in peer instruction and interactive engagement techniques has been shown to foster collaboration and reduce the gender gap in physics achievement $[98,99]$. Some women have reported that these techniques were essential in improving their science performance [100]. Hands-on laboratory work has been a source of improved science self-concept and motivation to pursue STEM careers for women [75,89]. A more diversified approach to physics teaching and learning will better serve both women and men.

Finally, a contributing factor to positive classroom environments for women is having a physics teacher with high expectations for them. Teachers with high standards who have expressed the belief that students can meet those standards have increased student motivation and performance and have reduced the achievement gap [101]. Students must experience respect and empowerment to trust that the teacher has confidence in their abilities; in doing so, students will not allow criticism to undermine 
their motivation and self-confidence. Critical feedback, shared assessment that communicates high standards and the instructor's belief in a student's potential, also strengthens trust between student and teacher [101]. By focusing on mastery goals and enhancing student autonomy, physics teachers can help students improve their motivation and self-efficacy [96]. This will strengthen the pipeline for physics participation.

\section{B. Personal encouragement and support}

One of the most common themes in science education research regarding women in physics is the social and emotional support of family, teachers, and peers. Many female physicists have stated that the support of their parents was crucial in their decision to enter the sciences $[36,70,74]$. Although teacher and parental support is important for all students, women have been shown to receive less teacher support than men [47]. Physics teachers should be aware of their responsibility to counter traditionally observed classroom behaviors. They can also reach out to families to educate parents about related career options and the need for familial support in STEM fields.

Encouragement from high school teachers and college faculty has also been shown to be influential. Women have frequently improved in physics when working with faculty who have accentuated the positive [56]. Encouraging teachers have been linked to stronger physics identities in women [49]. Also, teachers need to share the importance of physics, not just for STEM-related career paths but as a desirable course of study. Many women study physics to support other career goals $[9,33]$. Physics teachers and faculty can provide guidance to promising students who have demonstrated the interest and capacity to pursue physics [69]. An individual appeal to a young woman may provide the needed motivation to continue physics study [102].

\section{Role models}

Family role models have been important sources of selfefficacy for women in the sciences [42]; higher selfefficacy often leads to career entry behavior such as choice of college major [103]. Positive experiences with role models have reportedly helped women become more resilient in male-dominated professional environments $[36,87]$. The vicarious experience of seeing others perform physics tasks has often improved the self-efficacy of women, since they can envision their own success in similar roles [27,85]. Observing modeled behaviors by similar others has raised self-efficacy and helped formulate outcomes expectations [104]. Physics teachers can facilitate access to both female and male role models to counter sociocultural messages about the lack of women in physics. Physics faculty can share stories of their own career journeys to highlight the will power and commitment necessary to join the field. These actions may improve expectancies of success for women considering physics majors and careers.

\section{Curriculum-based reforms and institutional support}

Teachers and institutions have enacted reforms to attract more women into physics careers. The reforms have included curriculum-based strategies and institutionalbased efforts to promote equity in the field. Intrinsic motivation and planned behavior are closely related to the value that women place upon physics as a discipline. Consequently, it is essential that they perceive the relevance and authenticity of physics topics. Environmental factors are also considered since they influence behaviors related to career choices.

\section{Curriculum-based reforms}

Curriculum-based reforms have been rooted in two general areas: (i) emphasizing the topical relevance and societal benefits of physics, and (ii) suggesting more depth and less breadth in material covered. Interest-oriented physics instruction has been cited as particularly important for young women $[21,74]$. Authentic physics curricula have been shown to improve physics-related self-concept [41] and physics performance $[76,105]$. Curricula with realworld situations have been shown to improve women's physics identity [49]. Eisenkraft's Active Physics is one such example of a thematically organized curriculum that teaches physics through specific applications. The study of Active Physics implementation by Lawrenz et al. with 3119 students revealed that the gender achievement gap in physics performance lessened the longer the curriculum was in use [76].

In a broader context, women have frequently reported their desire to search for social meaning in physics study $[9,69]$. For example, Reid and Skrybina concluded that physics syllabi must include topics that have a balanced appeal for both girls and boys; doing so will improve attitudes towards physics for all students [9]. This has also been exemplified in women's tendency to speak of physics in more personal ways, often using anthropomorphic analogies to apply a physics concept to a nonscientific context [97]. Teachers should emphasize meaning and relevance in the exploration of physics topics.

\section{Institutional efforts}

Institutions have adopted several reforms to create more welcoming academic environments for female physics students. In a study conducted by the Committee on the Status of Women in Physics of the American Physical Society, Whitten et al. went on site visits to explore the climate for undergraduate women in physics departments [106]. When considering introductory courses, they recommended more interactive pedagogy and curricula as a 
means to attract more physics majors. Identifying women during their first year was one of the most successful strategies, whether through personal recruitment or integrating students into the social culture of the department. Some institutions had designated funding for these activities, such as Society of Physics Students chapters, paid assistantships, or social lounges for informal gatherings. Faculty were encouraged to implement interactive learning techniques, monitor student culture to root out biases, and emphasize the role of physics in environmental and other social issues. Physics departments that were successful in recruiting and retaining female physics majors were attentive to quality of life issues as well as curricular and classroom-based reforms [106].

\section{DISCUSSION AND CONCLUSIONS}

Table I outlines the relationships among the sociopsychological framework, strategies for improving women's participation in physics, and the source(s) for the enactment of these strategies. Mechanisms for reform are loosely categorized within the sociopsychological elements of physics selfconcept and self-efficacy, expectancy value and planned behavior, and motivation and self-determination. This organizational frame is not absolute, as there are areas of overlap among the themes. However, the outline serves to provide structure for empirically driven ways in which women may be recruited for physics participation. In an effort to highlight the most promising strategies, frequently cited recommendations will be discussed below.

The first paradigm involves physics self-concept and self-efficacy. This is the tendency of the woman to see herself as a physicist and whether she believes she can succeed in the corresponding academic work. These are socially constructed variables, dependent upon how one compares herself to others as well as her relative performance in physics compared to other subjects. Social feedback indicating success can strengthen self-efficacy and motivate a student to continue in the field [104]. Teachers may support women by communicating their beliefs in an incremental theory of intelligence, and providing critical feedback for students to have confidence they can achieve mastery. Self-efficacy is a strong predictor of grades [24], and it contributes to one's perseverance, resilience, and improved self-concept $[19,28,85]$.

The second paradigm, expectancy value and planned behavior, states that career-related choices are based upon probable envisioned outcomes and likelihood of success in achieving those outcomes. This construct is also related to self-efficacy and the perceived value of the career path. Women in physics have reported several social supports that were crucial in their choice of science. They received considerable support from family, teachers, and peers $[23,28]$. Role models helped women vicariously experience

TABLE I. Strategies for improving women's participation in physics.

\begin{tabular}{|c|c|c|}
\hline Sociopsychological paradigm & Strategies for improving participation (supporting references) & $\begin{array}{l}\text { Pedagogy-, curriculum-, } \\
\text { or institutionally based }\end{array}$ \\
\hline \multirow{7}{*}{$\begin{array}{l}\text { 1. Physics self-concept } \\
\text { and self-efficacy }\end{array}$} & Malleable or incremental theory of intelligence $[6,33,64,65,92,94,95]$ & Pedagogy \\
\hline & Activating prior knowledge $[25,75,76]$ & Pedagogy \\
\hline & Peer instruction or active learning techniques $[98,99,100]$ & Pedagogy \\
\hline & Active participation in hands-on laboratory activities $[54,55,75,89]$ & Pedagogy \\
\hline & Verbal explanations or fewer derivations $[53,87]$ & Pedagogy \\
\hline & High teacher expectations $[96,101]$ & Pedagogy \\
\hline & Multiple pathways for problem solving [52] & Pedagogy \\
\hline \multirow{5}{*}{$\begin{array}{l}\text { 2. Expectancy-value and } \\
\text { planned behavior }\end{array}$} & Encouragement or support & Pedagogy or Institutional \\
\hline & {$[28,36,49,50,51,52,56,71,74,83,84,85,86,87,102,106]$} & \\
\hline & Women role models $[6,28,36,42,48,56,67,73,102]$ & Institutional \\
\hline & Importance of physics to future goals $[9,29,33,52,56,69]$ & $\begin{array}{l}\text { Pedagogy or Curriculum/ } \\
\text { Institutional }\end{array}$ \\
\hline & Combating stereotypes $[48,56,58,82,106]$ & $\begin{array}{l}\text { Pedagogy or Curriculum or } \\
\text { Institutional }\end{array}$ \\
\hline \multirow[t]{7}{*}{$\begin{array}{l}\text { 3. Motivation and } \\
\text { self-determination }\end{array}$} & $\begin{array}{c}\text { Communal learning environments or welcoming departments } \\
\qquad[66,67,69,70,71,96,97,101,105,106]\end{array}$ & Pedagogy or Institutional \\
\hline & Topical relevance $[21,41,49,52,53,74,76,87,105]$ & $\begin{array}{l}\text { Pedagogy or Curriculum or } \\
\text { Institutional }\end{array}$ \\
\hline & Safe space for verbal expression $[49,54,55,66,68,69,75,76,98,101]$ & Pedagogy \\
\hline & Student autonomy $[28,69,75,90,96]$ & Pedagogy \\
\hline & Social benefits of physics $[9,42,69,97,106]$ & $\begin{array}{l}\text { Pedagogy or Curriculum or } \\
\text { Institutional }\end{array}$ \\
\hline & Self-selected groups $[66,68,87,96]$ & Pedagogy \\
\hline & More depth, less breadth $[88,106]$ & Curriculum \\
\hline
\end{tabular}


what their lives would be like as physicists, and they also dispelled negative stereotypes of physics as suitable for men more than women [36]. These expectancies can potentially influence physics persistence, particularly if the outcome is viewed as appealing, valuable, and attainable.

The final thematic element includes motivation and selfdetermination. For women, motivation is typically driven by intrinsic interest in physics. Self-determination is the degree of autonomy and controllability experienced by the student. Research has shown that several factors contribute to motivation. Collaborative and welcoming learning environments have provided a safe space for women to socially negotiate physics learning. Women have valued understanding the relevance of physics in their everyday worlds, as well as the broader significance of physics in promoting social justice. More in-depth study of physics topics facilitates the understanding that fosters relevance.

Physics educators and physics education researchers can apply psychological constructs to understand the social, environmental, and behavioral factors that influence women's choice of physics. Although traditional disparities in participation have persisted, social cognitive career theory and related themes provide an insightful framework for uncovering latent reasons for women's discouragement to choose physics. Teachers, faculty, and institutions may implement multifaceted, innovative reforms to create welcoming cultures that inspire more women to join the ranks of physicists.

\section{FUTURE RESEARCH}

The underrepresentation of women in physics is a persistent concern. A diversified STEM workforce is desirable and necessary, and women represent an underutilized resource in fulfilling their ranks. The physics community will benefit from multiple voices and varied perspectives. The cultural capital that women bring will help maximize creativity, innovation, and global prosperity [6].

Throughout this article, research on women in physics has been discussed from studies in physics education, science education, and sociopsychological domains. However, few of these studies have shown explicit connections between sociocognitive variables and the career trajectories of women in physics. Career aspirations are linked to self-assessment of competence in physics tasks [31]. Since some women consistently underrate their ability in physics, research is necessary to identify and transform the root social and cultural causes of this lack of confidence. Physics education researchers may explore several possible lines of inquiry.

Studies are needed to explore strategies leveraging social influences in improving women's physics self-concept. This might involve examining how peers affect women's diminished views of competence. Metacognition, or the ability of one to monitor her own learning, is a related consideration. Women's metacognition in physics may not accurately reflect their ability in the subject. By improving feelings of enjoyment and success, women may attain more accurate self-assessments. Social influences also extend to families. Research is needed on how families might act as a source of support in precollege and university physics settings. It would be promising to promote positive familial views of physics as a career path.

Role models are important sources of social influence for women in physics. There are many ways in which both men and women can model inclusive perspectives and work-life balance. Additional research may shed light on how students come to identify with prospective role models in physics, and how more faculty can serve in this capacity.

Studies are also needed to examine the role of physics teachers in improving attitudes and motivation. How might we train physics teachers to create learning environments conducive to social negotiation? Most programs in physics teacher education emphasize content expertise and pedagogical content knowledge, but it is also necessary to teach the sociopsychological aspects of learning physics. Research is needed on professional development treatments promoting social competence, critical feedback, facilitation of class discussion, equitable teaching practices, and creating positive atmospheres.

Sociopsychological theories of career choice have provided unique insights into women's views of physicists, physics students, and physics learning environments. Future studies can build upon this framework to identify fundamental social supports and cultural shifts in the physics community that may attract more women to physics majors and careers.

\section{ACKNOWLEDGMENTS}

The author would like to thank the reviewers for their thoughtful, detailed comments and suggestions to improve the manuscript. 
[1] American Physical Society, http://www.aps.org/ programs/education/statistics/womenstem.cfm.

[2] American Institute of Physics, http://www.aip.org/ statistics/data-graphics/percent-physics-master\%E2\%80\% 99s-earned-women-1983-through-2012.

[3] R. Ivie and K. N. Ray, http://www.aip.org/statistics/ reports/women-physics-and-astronomy-2005.

[4] American Physical Society, http://www.aps.org/programs/ women/workshops/gender-equity/upload/genderequity.pdf.

[5] National Academy of Sciences, Rising Above the Gathering Storm, Revisited: Rapidly Approaching Category 5 (National Academies Press, Washington, DC, 2010).

[6] C. Hill, C. Corbett, and A St. Rose, http://www.aauw.org/ research/why-so-few.

[7] President's Council of Advisors on Science \& Technology (PCAST), http://www.whitehouse.gov/sites/default/ files/microsites/ostp/pcast-engage-to-excel-final_feb.pdf.

[8] S. White and C. Langer, Tesfaye, http://www.aip.org/ statistics/reports/female-students-high-school-physics.

[9] N. Reid and E. A. Skryabina, Gender and physics, Int. J. Sci. Educ. 25, 509 (2003).

[10] O. Neuschmidt, J. Barth, and D. Hastedt, Trends in gender differences in mathematics and science (TIMMS 19952003), Stud. Educ. Eval. 34, 56 (2008).

[11] L. Aguilar, G. Walton, and C. Wieman, Psychological insights for improved physics teaching, Phys. Today 67, No. 5, 43 (2014).

[12] R. W. Lent, S. D. Brown, and G. Hackett, Toward a unifying social cognitive theory of career and academic interest, choice, and performance, J. Vocat. Behav. 45, 79 (1994).

[13] A. Bandura, Social cognitive theory: An agentic perspective, Annu. Rev. Psychol. 52, 1 (2001).

[14] A. Bandura, Social Foundations of Thought and Action: A Social Cognitive Theory (Prentice Hall, Englewood Cliffs, NJ, 1986).

[15] G. Hackett, N. E. Betz, J. M. Casas, and I. A. RochaSingh, Gender, ethnicity, and social cognitive factors predicting the academic achievement of students in engineering, J. Counsel. Psychol. 39, 527 (1992).

[16] A. Bandura, Social cognitive theory in a cultural context, Appl. Psychol. 51, 269 (2002).

[17] X. Wang, Modeling Student Choice of STEM Fields of Study: Testing a Conceptual Framework of Motivation, High School Learning, and Postsecondary Context of Support (Wisconsin Center for the Advancement of Postsecondary Education, Madison, WI, 2012).

[18] S. J. Ceci, W. M. Williams, and S. M. Barnett, Women's underrepresentation in science: Sociocultural and biological considerations, Psychol. Bull. 135, 218 (2009).

[19] G. Hardy, Academic self-concept: Modeling and measuring for science, Res. Sci. Educ. 44, 549 (2014).

[20] J. Möller and H. W. Marsh, Dimensional comparison theory, Psychol. Rev. 120, 544 (2013).

[21] L. Hoffman, Promoting girls' interest and achievement in physics classes for beginners, Learn. Instr. 12, 447 (2002).

[22] B. Nagengast and H. W. Marsh, Big fish in little ponds aspire more: Mediation and cross-cultural generalizability of school-average ability effects on self-concept and career aspirations in science, J. Educ. Psychol. 104, 1033 (2012).

[23] M. Jansen, U. Schroeders, and O. Lüdtke, Academic selfconcept in science: Multidimensionality, relations to achievement measures, and gender differences, Learn Indiv. Differ. 30, 11 (2014).

[24] S. L. Britner, Motivation in high school science students: A comparison of gender differences in life, physical, and Earth science classes, J. Res. Sci. Teach. 45, 955 (2008).

[25] A. M. L. Cavallo, W. H. Potter, and M. Rozman, Gender differences in learning constructs, shifts in learning constructs, and their relationship to course achievement in a structured inquiry, yearlong college physic course for life science majors, School Sci. Math. 104, 288 (2004).

[26] R. W. Lent, S. D. Brown, and K. C. Larkin, Relation of self-efficacy expectations to academic achievement and persistence, J. Counsel. Psychol. 31, 356 (1984).

[27] V. Sawtelle, E. Brewe, and L. H. Kramer, Exploring the relationship between self-efficacy and retention in introductory physics, J. Res. Sci. Teach. 49, 1096 (2012).

[28] L. Leslie, G. McClure, and R. Oaxaca, Women and minorities in science and engineering: A life sequence analysis, J. Higher Educ. 69, 239 (1998).

[29] J. Eccles and A. Wigfield, Motivational beliefs, values, and goals, Annu. Rev. Psychol. 53, 109 (2002).

[30] J. Abraham and K. Barker, An expectancy-value model for sustained enrollment intentions of senior secondary physics students, Res. Sci. Educ. 45, 509 (2014).

[31] S. J. Correll, Constraints into preferences: Gender, status, and emerging career aspirations, Am. Soc. Rev. 69, 93 (2004).

[32] P. Haussler and L. Hoffman, An intervention study to enhance girls' interest, self-concept, and achievement in physics classes, J. Res. Sci. Teach. 39, 870 (2002).

[33] T. DeBacker and R. Nelson, Motivation to learn science: Differences related to gender, class type, and ability, J. Educ. Res. 93, 245 (2000).

[34] S. J. Ceci and W. M. Williams, Understanding current causes of women's underrepresentation in science, Proc. Natl. Acad. Sci. U.S.A. 108, 3157 (2011).

[35] I. Ajzen, Perceived behavioral control, self-efficacy, locus of control, and the theory of planned behavior, J. Appl. Soc. Psychol. 32, 665 (2002).

[36] L. S. Richman, M. Van Dellen and W. Wood, How women cope: Being a numerical minority in a maledominated profession, J. Soc. Issues 67, 492 (2011).

[37] S. M. Glynn, P. Brickman, N. Armstrong, and G. Taasoobshirazi, Science Motivation Questionnaire II: Validation with science majors and non-science majors, J. Res. Sci. Teach. 48, 1159 (2011).

[38] T. K. DeBacker and R. M. Nelson, Variations on an expectancy-value model of motivation in science, Contemp. Educ. Psychol. 24, 71 (1999).

[39] R. M. Ryan and E. L. Deci, Self-determination theory and the facilitation of intrinsic motivation, social development, and well-being, Am. Psychol. 55, 68 (2000).

[40] R. M. Ryan and E. L. Deci, Intrinsic and extrinsic motivations: Classic definitions and new directions, Contemp. Educ. Psychol. 25, 54 (2000). 
[41] P. Haussler and L. Hoffman, A curricular frame for physics education: Development, comparison with students' interests, and impact on students' achievement and self-concept, Sci. Educ. 84, 689 (2000).

[42] R. Koul, T. Lerdpornkulrat, and S. Chantara, Relationship between career aspirations and measures of motivation toward biology and physics, and the influence of gender, J. Sci. Educ. Technol. 20, 761 (2011).

[43] H. Carlone, The cultural production of science in reformbased physics: Girls' access, participation, and resistance, J. Res. Sci. Teach. 41, 392 (2004).

[44] A. C. Barton, E. Tan, and A. Rivet, Creating hybrid spaces for engaging school science among urban middle school girls, Am. Educ. Res. J. 45, 68 (2008).

[45] E. Tan and A.C. Barton, Unpacking science for all through the lens of identities-in-practice: The stories of Amelia and Ginny, Cult. Stud. Sci. Educ. 3, 43 (2008).

[46] A. C. Barton, Science education in urban settings: Seeking new ways of praxis through critical ethnography, J. Res. Sci. Teach. 38, 899 (2001).

[47] I. Esmonde, Ideas and identities: Supporting equity in cooperative mathematics learning, Rev. Educ. Res. 79, 1008 (2009).

[48] M. Ong, Body projects of young women of color in physics: Intersections of gender, race, and science, Soc. Probl. 52, 593 (2005).

[49] Z. Hazari, G. Sonnert, P. M. Sadler, and M. C. Shanahan, Connecting high school physics experiences, outcome expectations, physics identity, and physics career choice: A gender study, J. Res. Sci. Teach. 47, 978 (2010).

[50] G. Taasoobshirazi and M. Carr, Gender differences in science: An expertise perspective, Educ. Psychol. Rev. 20, 149 (2008).

[51] T. Lyons, The puzzle of falling enrollments in physics and chemistry courses: Putting some pieces together, Res. Sci. Educ. 36, 285 (2006).

[52] T. Mujtaba and M. J. Reiss, Inequality in experiences of physics education: Secondary school girls' and boys' perceptions of their physics education and intentions to continue with physics after the age of 16, Int. J. Sci. Educ. 35, 1824 (2013).

[53] C. Angell, O. Guttersrud, and E. K. Henriksen, Physics: Frightful but fun: Pupils' and teachers' views of physics and physics teaching, Sci. Educ. 88, 683 (2004).

[54] B. Guzzetti and W. O. Williams, Gender, text, and discussion: Examining intellectual safety in the science classroom, J. Res. Sci. Teach. 33, 5 (1996).

[55] K. Tobin, Differential engagement of male and females in high school science, Int. J. Sci. Educ. 10, 239 (1988).

[56] M. Fehrs and R. Czujko, Women in physics: Reversing the exclusion, Phys. Today 45, No. 8, 33 (1992).

[57] A. Aprahamian, Women in physics, Nucl. Phys. News 13, 3 (2003).

[58] S. J. Farenga and B. A. Joyce, Intentions of young students to enroll in science courses in the future: An examination of gender differences, Sci. Educ. 83, 55 (1999).

[59] L. McCullough, Women in physics: A review, Phys. Teach. 40, 86 (2002).
[60] T. Schmader, M. John, and C. Forbes, An integrated process model of stereotype threat effects on performance, Psychol. Rev. 115, 336 (2008).

[61] S. J. Spencer, C. M. Steele, and D. M. Quinn, Stereotype threat and women's math performance, J. Exp. Soc. Psychol. 35, 4 (1999).

[62] C. M. Steele, A threat in the air: How stereotypes shape intellectual identity and performance, Am. Psychol. 52, 613 (1997).

[63] C. M. Steele, S. J. Spencer, and J. Aronson, Contending with group image: The psychology of stereotype and social identity threat, Adv. Exp. Soc. Psychol. 34, 379 (2002).

[64] C. Good, J. Aronson, and M. Inzlicht, Improving adolescents' standardized test performance: An intervention to reduce the effects of stereotype threat, J. Appl. Dev. Psychol. 24, 645 (2003).

[65] G. C. Marchand and G. Taasoobshirazi, Stereotype threat and women's performance in physics, Int. J. Sci. Educ. 35, 3050 (2013).

[66] E. Alexoopoulou and R. Driver, Gender differences in small group discussion in physics, Int. J. Sci. Educ. 19, 393 (1997).

[67] A. Zohar and D. Sela, Her physics, his physics: Gender issues in Israeli advanced placement physics classes, Int. J. Sci. Educ. 25, 245 (2003).

[68] K. Williams, Understanding, communication anxiety, and gender in physics: Taking the fear out of physics learning, J. Coll. Sci. Teach. 30, 232 (2000).

[69] A. Zohar and B. Bronshtein, Physics' teachers knowledge and beliefs regarding girls' low participation rates in advanced physics classes, Int. J. Sci. Educ. 27, 61 (2005).

[70] K. P. Dabney and R. H. Tai, Female physicist doctoral experiences, Phys. Rev. ST Phys. Educ. Res. 9, 010115 (2013).

[71] M. S. Dresselhaus, J. R. Franz, and B. C. Clark, Interventions to increase the participation of women in physics, Science 263, 1392 (1994).

[72] J. V. Mallow, Gender-related science anxiety: A first binational study, J. Sci. Educ. Technol. 3, 227 (1994).

[73] M. K. Udo, G. P. Ramsey, S. Reynolds-Alpert, and J. V. Mallow, Does physics teaching affect gender-based science anxiety?, J. Sci. Educ. Technol. 10, 237 (2001).

[74] A. Sahin, O. Gulacar, and C. Stuessy, High school students' perceptions of the effects of International Science Olympiad on their STEM career aspirations and twenty-first century skill development, Res. Sci. Educ. 45, 785 (2014).

[75] P. Labudde and W. Herzog, Girls and physics: Teaching and learning strategies tested by classroom interventions in grade 11, Int. J. Sci. Educ. 22, 143 (2000).

[76] F. Lawrenz, N. B. Wood, A. Kirchoff, N. K. Kim, and A. Eisenkraft, Variables affecting physics achievement, J. Res. Sci. Teach. 46, 961 (2009).

[77] P. Murphy, S. Lunn, and H. Jones, The impact of authentic learning on students' engagement with physics, Curr. J. 17, 229 (2006).

[78] J. Osbourne and S. Collins, Pupils' views of the role and value of the science curriculum: A focus group study, Int. J. Sci. Educ. 23, 441 (2001). 
[79] D. Nelson, http://faculty-staff.ou.edu/N/Donna.J.Nelson-1/ diversity/Faculty_Tables_FY07/07Report.pdf.

[80] K. N. Rask and E. M. Bailey, Are faculty role models? Evidence from major choice in an undergraduate institution, J. Econ. Educ 33, 99 (2002).

[81] American Institute of Physics, http://www.aip.org/sites/ default/files/statistics/highschool/hs-whoteaches-13.pdf.

[82] U. Kessels and R. Taconis, Alien or alike? How the perceived similarity between the typical science teacher and a student's self-image correlates with choosing science at school, Res. Sci. Educ. 42, 1049 (2012).

[83] Z. Hazari, P. M. Sadler, and R. H. Tai, Gender differences in the high school and affective experiences of introductory college physics students, Phys. Teach. 46, 423 (2008).

[84] R. Ivie, R. Czujko, and K. Stowe, Women Physicists Speak: The 2001 International Study of Women in Physics (AIP Statistical Research Center, College Park, MD, 2002), https://www.aip.org/sites/default/files/ statistics/women/women-speak-01.pdf.

[85] A. L. Zeldin and F. Pajares, Against the odds: Self-efficacy beliefs of women in mathematical, scientific, and technological careers, Am. Educ. Res. J. 37, 215 (2000).

[86] A. van Lengen, L. Rekers-Mombarg, and H. Dekkers, Sex-related differences in determinants and process of science and mathematics choice in pre-university education, Int. J. Sci. Educ. 28, 71 (2006).

[87] J. A. Schuck and M. Fish, Factors contributing to the underrepresentation of women in physics-based engineering fields, Proceedings of the 1997 WEPAN/NAMEPA Joint National Conference: "Impacting Change Tbrough Collaboration” (1997), p. 143.

[88] E. Seymour, Why undergraduates leave the sciences, Am. J. Phys. 63, 199 (1995).

[89] M. Jansen, R. Scherer, and U. Schroeders, Students' selfconcept and self-efficacy in the sciences: Differential relations to antecedents and educational outcomes, Contemp. Educ. Psychol. 41, 13 (2015).

[90] F. McDonnell, Why so few choose physics: An alternative explanation for the leaky pipeline, Am. J. Phys. 73, 583 (2005).

[91] P. Murphy and E. Whitelegg, Girls and physics: Continuing barriers to belonging, Curr. J. 17, 281 (2006).

[92] J. Aronson, C. B. Fried, and C. Good, Reducing the effects of stereotype threat on African American college students by shaping theories of intelligence, J. Exp. Soc. Psychol. 38, 113 (2002).
[93] C. S. Dweck, C.-y. Chiu, and Y.-y. Hong, Implicit theories and their role in judgments and reactions: A word from two perspectives, Psychol. Inquiry: Int. J. Adv. Psychol. Theory 6, 267 (1995).

[94] L. S. Blackwell, K. H. Trzesniewski, and C. S. Dweck, Implicit theories of intelligence predict achievement across an adolescent transition: A longitudinal study and an intervention, Child Development 78, 246 (2007).

[95] C. S. Dweck and E. L. Leggett, A social-cognitive approach to motivation and personality, Psychol. Rev. 95, 256 (1988).

[96] C. M. Rubie-Davies, E. R. Peterson, C. G. Sibley, and R. Rosenthal, A teacher expectation intervention: Modelling the practices of high expectation teachers, Contemp. Educ. Psychol. 40, 72 (2015).

[97] H. Stadler, R. Duit, and G. Benke, Do boys and girls understand physics differently?, Phys. Educ. 35, 417 (2000).

[98] M. Lorenzo, C. H. Crouch, and E. Mazur, Reducing the gender gap in the physics classroom, Am. J. Phys. 74, 118 (2006).

[99] J. Watkins and E. Mazur, Retaining students in science, technology, engineering, and mathematics (STEM) majors, J. Coll. Sci. Teach. 42, 36 (2013).

[100] A. J. Welsh, Exploring undergraduates' perceptions of the use of active learning techniques in science lectures, J. Coll. Sci. Teach. 42, 80 (2012).

[101] D. S. Yeager, V. Purdie-Vaughns, J. Garcia, N. Apfel, P. Brzustoski, A. Master, W. T. Hessert, M. E. Williams, and G. L. Cohen, Breaking the cycle of mistrust: Wise interventions to provide critical feedback across the racial divide, J. Exp. Psychol. 143, 804 (2014).

[102] M. B. Schneider, Encouragement of women physics majors at Grinnell College: A case study, Phys. Teach. 39, 280 (2001).

[103] R. W. Lent, F. G. Lopez, and K. J. Bieschke, Mathematics self-efficacy: Sources and relation to science-based career choice, J. Counsel. Psychol. 38, 424 (1991).

[104] D. H. Schunk, Social-self interaction and achievement behavior, Educ. Psychol. 34, 219 (1999).

[105] G. Stewart and J. Osborn, Closing the gender gap in student confidence: Results from a University of Arkansas physics class, J. Women Minorities Sci. Eng. 4, 27 (1998).

[106] B. L. Whitten, S. R. Foster, and M. L. Duncombe, What works for women in undergraduate physics?, Phys. Today 56, No. 9, 46 (2003). 